\title{
ALICANTE (1900-1910)
}

\section{Francisco Reus Boyd-Swan}

\author{
Universidad de Alicante \\ F.A.Reus@ua.es
}

Las Compañías que actuaron en los diversos teatros alicantinos durante los diez primeros años del siglo XX fueron en total sesenta, de las cuales treinta pertenecen a un tipo de teatro declamado, veintisiete interpretaban teatro lírico y tres se dedicaban a la ópera.

\section{COMPAÑía CóMICO-DRAMÁTICA BALAGUER-LARRA}

El día 6 de marzo de 1908 hace su presentación en el Teatro Principal esta compañía, que permanece en él hasta el día 16. Estaba formada por los siguientes artistas:

Luis M. de Larra, director Aniceto Alemán Luis Manrique

Consuelo Abad Clotilde Feros
Juan Balaguer, primer actor Manuel Balaguer Antonio Tornel Josefa Alcoba Antonia Sánchez
Concha Catalá, 1. actriz Francisco Ares Enrique Navas Rafael Yáñez Agustín Valle Isabel Burillo Carmen Catalá 
El precio de la entrada era de 0,75 ptas. y las obras que llevaban en su repertorio fueron:

$\begin{array}{llll}\text { El barón de Tronco Verde } & \text { El afinador } & \text { Mañana de sol } & \text { El genio alegre } \\ \text { El doctor Giménez } & \text { La rebotica } & \text { Nido de áaguilas } & \text { El oso muerto } \\ \text { El chiquitín de la casa } & \text { El sombrero de copa } & \text { El Tenorio modernista } \\ \text { El niño prodigio } & \text { Los incasables } & \text { Prueba de almas } & \text { Una cana al aire } \\ \text { Alrededor del mundo } & \text { La muela del juicio } & \text { El amor que pasa Los asistentes } \\ \text { La victoria del general } & \text { Los monigotes } & \text { Divorciémonos } & \text { Las flores. } \\ \text { El matrimonio interino } & \text { El patio } & & \end{array}$

La compañía vuelve a ocupar el escenario del Principal desde el día 28 de octubre del mismo año hasta el 7 de noviembre, para representar:

$\begin{array}{llll}\text { Los chorros del oro } & \text { Las de Caín } & \text { La fuerza bruta } & \text { Lo que no muere } \\ \text { Chifladuras } & \text { Mi cara mitad } & \text { La ducha } & \text { Don Juan Tenorio } \\ \text { La escondida senda } & \text { El oso muerto } & \text { El amor asusta } & \text { La cizaña } \\ \text { El incierto porvenir } & \text { Morada histórica } & \text { Doña Clarines } & \text { El afinador } \\ \text { La victoria del general } & \text { El baile de la condesa } & \text { El agua milagrosa Por las nubes. }\end{array}$

Tuvo esta compañía una buena acogida, pues incluso antes de llegar a Alicante, la prensa iba preparando el camino, con una buena propaganda, en la que cualquier motivo era suficiente para comentar algo sobre ella:

\begin{abstract}
Podemos asegurar a nuestros lectores en contestación a la pregunta que por diferentes conductos nos han hecho, que la compañía Balaguer-Larra no ha pensado ni remotamente poner en escena los clásicos «Tenorios" durante la corta temporada que ha de actuar en nuestro coliseo. Ambos directores, conocedores de que el género dramático se aparta en un todo de las condiciones de los artistas de su excelente compañía, que cultivan otro muy distinto, con una conciencia artística poco corriente hoy en día, desprecian como empresarios un puñado de pesetas antes que exponerse a hacer el ridículo (Diario de Alicante, n. ${ }^{\circ} 814,27-\mathrm{X}-09, \mathrm{p} .2$ ).
\end{abstract}

Después veremos que sí se hizo el Tenorio, lo cual hace pensar que todo fue propaganda. De todas formas, la compañía cumplió bien su cometido:

Anoche la farándula llevó unas horas de bien al espíritu burgués del público del Teatro Principal. La compañía que dirigen Balaguer y Larra vino a Alicante y su debut nos proporcionó medicina curadora del empacho de nuestro gusto, un mucho estragado por artistas y arte de baja estofa. El público llevaba en su semblante muestra elocuente de satisfacción y al des- 
correrse la cortina, aire reconfortador salió del proscenio a la sala. Mutuas corrientes de simpatía se establecieron entre comediantes y espectadores.

Cuando por primera vez vimos Las de Caín, quizá la más endeble de cuantas brotaron de sus plumas como ya dijimos a raíz de representarla Thuillier, nos asaltó la duda de si podría ser hija del mismo ingenio que creara "El amor que pasa», «Los galeotes», etc.

Anoche la acción no pareció tan pesada al público y Larra y Balaguer hicieron de sus papeles tales creaciones que el espectador que llamó aburrida y ñoña a la obra en otra ocasión, súpole a poco cuanto le daban y gozó extraordinariamente de las condiciones admirables de casamentero del señor Caín...

(Diario de Alicante, n. ${ }^{\circ} 816,29-\mathrm{X}-09$, p. 2).

Sin embargo, conforme pasan los días, el mismo crítico va perdiendo calor en sus apreciaciones sobre la compañía y empiezan a aparecer algunas notas negativas, quizá más achacables al tipo de obras representadas:

El cronista debe consignar aunque parezca paradoja que en los dias pasados no ha habido más novedad en el Teatro Principal que la representación de La ducha. El lector que habrá visto en los carteles el anuncio del estreno de La escondida senda y el de la representación de varias distintas obras más, se quedará un poco perplejo al leer lo que al comenzar he escrito. $Y$ no me arrepiento de ello. La ducha, ese juguete cómico con ribetes de «vaudevile» de Pina Domínguez, que tanto gusto dio a nuestros abuelos, ha sido el último éxito de la compañía Larra-Balaguer.

$Y$ es que el género les va bien a los artistas del Principal como se dice en el argot entre bastidores, yéndoles no tan bien el otro género. Da muestras de ello la representación del clásico e inolvidable "Tenorio» en cuya interpretación solamente se distinguió Miguel Soler.

La escondida senda no llegó al público. Es demasiado pesada. Su acción languidece de forma alarmante y al final el espectador llega a los límites del aburrimiento. Aprovechando el patrón con que confeccionaron los Quintero El amor que pasa, han hecho otras obras no tan afortunadas como aquélla. A ellas pertenece La escondida senda que, no obstante su acabada interpretación, no hizo mella en el ánimo de la concurrencia. En cambio en La ducha el éxito fue de los que no se olvidan. La venerable obra de Pina fue bordada por todos los artistas y nos pareció nueva. Los aplausos fueron tan continuados como las risas del espectador y al final la cortina tuvo que ser levantada varias veces.

(Diario de Alicante, $.^{\circ} 818,2-\mathrm{XI}-09$, p. 2).

\section{COMPAÑía DE ÓPERA ITALIANA DE ARTURO BARATTA}

El día diecinueve de marzo de 1903 hizo su presentación en el Teatro Principal. Su elenco lo formaban: 


$\begin{array}{llll}\text { Arturo Baratta } & \text { Filipo d'Ottavi } & \text { Güelfo Mazzi } & \text { Vicenzo Costani } \\ \text { José Pascual } & \text { Luigi Vicentini } & \text { Adela Botti } & \text { Lelio Casini } \\ \text { Adalgisa Minotti } & \text { Alfredo Serazzi } & \text { Adriana Palermi Lery } & \text { Francisco Vila. } \\ \text { María Claessens } & \text { Baltasar Banquells } & & \end{array}$

Tenía además una orquesta formada por treinta profesores del Gran Teatro del Liceo de Barcelona y un extraordinario coro, ayudado por otro coro de niños. Era, pues, una verdadera compañía italiana que llegó a Alicante avalada por gran fama y cuyas actuaciones resultaron notables acontecimientos teatrales y sociales. Se mantuvieron en el Principal hasta el día 5 de abril y volvieron al mismo escenario en un vacío de actuaciones entre los días 20 al 23 de mayo. El público acudió en masa al teatro y lo llenó todas las funciones, por lo que resultó un éxito artístico y, parece ser, económico para la empresa, con la entrada general al precio de 1 peseta, alto para la época.

Puso en escena esta compañía:

$\begin{array}{llll}\text { Tosca } & \text { Il Trovatore } & \text { Lucrezia Borgia } & \text { Faust } \\ \text { La Bohème } & \text { La Favorita } & \text { Rigoletto } & \\ \text { Gli Ugonotti } & \text { Cavalleria Rusticana } & \text { Hansel und Gretel } & \end{array}$

En 1904, desde el 18 de febrero hasta el dos de marzo, vuelve a actuar en el Principal, poniendo en escena:

$\begin{array}{lllll}\text { La Bohème } & \text { Andrea Chenier } & \text { Faust } & \text { I Pagliacci } & \text { Rigoletto } \\ \text { Cavalleria Rusticana } & \text { Carmen } & \text { Tosca } & \text { La Africana } & \end{array}$

Dice Vicente Ramos que en estas jornadas hizo su presentación con la compañía la tiple sevillana Elena Fons, con la ópera Carmen.

La misma compañía ocupa de nuevo el escenario del Teatro Principal del 14 al 29 de enero de 1905, con algunas variaciones en su elenco, que quedó así:

$\begin{array}{llll}\text { Enriqueta Aceña } & \text { Anita Lopetegui } & \text { Adriana Palermo } & \text { Juanita Parés } \\ \text { Luisa Polo } & \text { Beatriz Costa } & \text { Fernanda Duval } & \text { Luis Iribarne } \\ \text { Mariano Serra } & \text { Antonio Saludas } & \text { Francisco Molins } & \text { Francisco Puigcerver. } \\ \text { Juan Romeu } & \text { Manuel Carbonell } & & \end{array}$


Como se puede observar, muchos de los componentes de la compañía eran ya españoles. Representaron en esta ocasión:

$\begin{array}{llll}\text { Tosca } & \text { Gli Ugonotti } & \text { La Bohème } & \text { Faust } \\ \text { La Favorita } & \text { Aida } & \text { Rigoletto } & \text { La Africana }\end{array}$

Entre el 28 de octubre y el 12 de noviembre del mismo año volvió a actuar, presentando las novedades de Cuentos de Hoffman, Hernani y Lohengrin, junto a obras que ya habían representado aquí.

Otra vez que la compañía estuvo en Alicante fue desde el día 11 al 19 de enero de 1907, con dos óperas nuevas en su repertorio: Sansón y Dalila y La condenación de Fausto.

La crítica dijo de esta compañía el día que debutó:

Si por desgracia no se hallara tan desacreditado el tópico periodístico, calificaría de verdadero acontecimiento teatral el debut de la compañía de ópera que tuvo efecto anoche en el Principal. Ofrecía el coliseo el aspecto de las grandes solemnidades: casi llenas por completo las localidades, donde ostentaban sus encantos nuestras lindas paisanas; atestadas de concurrencia las galerías altas; veíase a las claras el interés que despertó en el público el estreno de la grandiosa ópera "Tosca».

$Y$ todo lo merece el santo, es decir Giacomo Puccini, que es el que ha obrado el milagro de cautivar por completo la atención de los verdaderos aficionados, embelesándonos perdón por la inmodestia - con los acentos siempre inspiradísimos de sus brillantes partituras.

Si «La Bohème» es un prodigio, "Tosca» es una maravilla, a pesar del género harto diferente cultivado por Puccini en una y otra ópera. No contento con vencer en toda la línea narrando de un modo sublime por medio del pentagrama las regocijadas escenas de la vida bohemia, parece que ha echado mano en «Tosca» del repertorio terrorífico y espeluznante para ofrecernos otra muestra gallardísima de la universalidad de su talento. No es suficiente, y sabe a poco además, una sola audición de esta última obra para aquilatar su mérito artístico. Apenas si deja espacio para saborear muchos números tan repletos de brillante sonoridad como llenos de inspiradas melodias y maravillosos efectos orquestales.

Mis lectores me agradecerán que les recomiende oigan la ópera cuando tengamos la fortuna de que sea nuevamente cantada, a que me enfrasque aquí en un laberinto descriptivo de sus bellezas (El Noticiero, $n .^{\circ} 1705,20-$ III-1903, p. 2).

A pesar de estas alabanzas, el mismo crítico censura unos días después la propensión de la compañía hacia un repertorio más moderno, así como los arreglos de obras clásicas: 
El modernismo se impone hasta en las fusas y semicorcheas. Y la empresa de la compañía de ópera que actúa en este coliseo demuestra tener tan extraordinario apego a las modernas corrientes musicales, como injustificable desvio por las partituras del repertorio antiguo. Asi es que cuando vemos anunciada en nuestros carteles una de esas óperas que causaron las delicias de nuestros abuelos, nos echamos a temblar instintivamente.

Anoche le tocó a Gounod y si algún aficionado acudió al coliseo relamiéndose por anticipado con las bellezas de «Faust» debió salir pensando cuán fácil es errar en este bajo suelo. Lo cual no significa, ni mucho menos, que la debutante señorita Menotti no hiciera esfuerzos sobrehumanos en el desempeño de su cometido, ni que el tenor, señor Cortani, no cantara muy acertadamente algunos trozos de su particella; ni que el bajo, señor Banquells no confirmara el lisonjero juicio que de él formamos como cantante al escucharlo en "Lucrezia Borgia». Pero... (estos puntos significan que el público preferiría más «Toscas» y «Bohèmes») (El Noticiero, n. ${ }^{\circ} 1708,24-$ III-1903, p. 3).

\section{COMPAÑíA LÍRICA DIRIGIDA POR ANTONIO GARCÍA IBÁÑ̃EZ}

El día 4 de febrero de 1905 debía haber debutado esta compañía en el Principal, pero por lo visto los equipajes se habían extraviado en alguna estación de ferrocarril antes de llegar a Alicante. Tuvieron que suspenderse todas las actuaciones hasta el día siguiente. La despedida se produjo el día 7 de marzo. Traían en cartera un repertorio largo y durante su estancia en Alicante representaron:

$\begin{array}{llll}\text { La revoltosa } & \text { Bohemios } & \text { La tragedia de Pierrot } & \text { Los pícaros celos } \\ \text { El barbero de Sevilla } & \text { El dúo de la Africana } & \text { El pobre Valbuena } & \text { El mozo crúo } \\ \text { La verbena de la Paloma } & \text { La Macarena } & \text { La banda de trompetas } & \text { Carceleras } \\ \text { El rey del valor } & \text { Enseñanza libre } & \text { El cabo primero } & \text { La golfemia } \\ \text { María de los Ángeles } & \text { La buena sombra } & \text { La polka de los pájaros } & \text { Venus-Salón } \\ \text { El puñao de rosas } & \text { Doloretes } & \text { Los zapatos de charol } & \text { La mazorca roja } \\ \text { La fiesta de san Antón } & \text { El bateo } & \text { El húsar de la guardia } & \text { La buena moza. } \\ \text { Los chicos de la escuela } & & \text { Una vieja } & \end{array}$

Esta compañía tuvo algunos problemas que obligaron a suspender las funciones los días 7 y 21 de febrero. La causa en ambas ocasiones parecieron ser los roces con la orquesta, a pesar de lo cual siguió actuando con bastante dignidad.

En 1906, de nuevo actúan en el Principal, desde el 11 hasta el 27 de febrero. Formaban la compañía, además del maestro director-concertador, Francisco Lozano: 
Purificación Cancela Vicente Férriz
Amalia Menéndez

Miguel Lluch
Crisanta Blasco

Francisco Macías
Ángela Figuerola

Joaquín Possac.

Mediante el sistema de funciones por secciones, fueron poniendo en escena un buen número de obras, con la representación de algunas que no habían traído en la anterior ocasión, como:

$\begin{array}{llll}\text { Los granujas } & \text { El monaguillo } & \text { Château-Margaux } & \text { El contrabando } \\ \text { El trébol } & \text { Las estrellas } & \text { Moros y Cristianos } & \text { Marina } \\ \text { La tempranica } & \text { Los guapos } & \text { El alma del pueblo } & \text { La casita blanca } \\ \text { La reina mora } & \text { La alegría de la huerta } & \text { La Czarina } & \text { La trapera. } \\ \text { La marcha de Cádiz } & \text { La tempestad } & & \end{array}$

La compañía tuvo algunos problemas durante estos días. Así, la función del día 15 su tuvo que suspenderse por «indisposición de la señorita taquillera». Y lo mismo ocurrió con la del día 19, aunque en esta ocasión el motivo fue el despido de la tiple Amalia Menéndez, que se negó a trabajar si no se le concedía un aumento de sueldo. García Ibáñez no accedió y se solucionó el conflicto sin realizar nuevos contratos. Por ello hubo algunos días sin actuación de esta compañía.

Vuelve al Principal en el año 1909, actuando solamente en los días 2,4 y 6 de febrero. Los precios de la entrada eran de 0,20 pesetas y los componentes de la compañía eran:

$\begin{array}{llll}\text { Julita Campos } & \text { Antonia Cachavera } & \text { Amparo Moyá } & \text { Soledad Molina. } \\ \text { Juan Bordás } & \text { Santiago León } & \text { José Viñas } & \end{array}$

En esta corta estancia, representaron:

San Juan de Luz

El ratón

La república del amor
La carne flaca

El lobato

Bohemios
Las bribonas El terrible Pérez

Los dos rivales
¡Apaga y vámonos!

El estudiante

Los niños de Tetuán.

\section{COMPAÑÍA DE FRANCISCO GARCÍA ORTEGA}

Los actores de esta compañía aparecían así en el programa de mano: 


$\begin{array}{lllll}\text { Sra. Alverá } & \text { Sra. Nestosa } & \text { Sra. Blanco } & \text { Sra. Suja } \\ \text { Sta. Rodríguez } & \text { Sra. Bagá } & \text { Sta. Peña } & \text { Sr. Aguado } \\ \text { Sr. Castilla } & \text { Sr. Randa } & \text { Sr. Valle } & \text { Sr. Parradón } & \text { Sr. López } \\ \text { Sr. Chorro } & \text { Sr. Soto } & \text { Sr. Barrera } & \text { Sr. Agudín } & \text { Sr. Fernández. }\end{array}$

Estuvieron en Alicante, en el Principal, desde el día 22 de abril al 4 de mayo de 1902 , con un precio de entrada de 0,55 pesetas. Pusieron en escena las siguientes obras:

Felipe Derblay

En el seno de la muerte

El trapero de Madrid

La gobernadora
El patio

Don Álvaro o la fuerza del sino

El himno de Riego

Lo cursi
Tortosa y Soler

La criatura

La novela de la vida

Los galeotes.

Mujer gazmoña y marido infiel El regimiento de Lupión

Esta compañía volvió a actuar en el Principal, desde el día 15 de diciembre de 1909 hasta el 10 de enero de 1910. Como primeras figuras seguían apareciendo Josefina Nestosa y Sofía Alverá. El precio de la entrada se fijó en 0,50 pesetas y durante esta nueva estancia en Alicante se ofrecieron:

\author{
Doña Clarines \\ Los ojos de los muertos \\ El libre cambio \\ El ladrón \\ Demi-Monde \\ El zapatero y el rey \\ Los martes de las de Gómez \\ D. Álvaro o la fuerza del sino \\ Raffles el elegante \\ En el seno de la muerte \\ El adversario \\ Las tres jaquecas \\ El alcalde de Zalamea
}

$\begin{array}{ll}\text { Felipe Derblay } & \text { El marido de su viuda } \\ \text { Amor a oscuras } & \text { El tanto por ciento } \\ \text { O locura o santidad } & \text { Sangre gorda } \\ \text { La loca de la casa } & \text { Tristes amores } \\ \text { El sombrero de copa } & \text { La zagala } \\ \text { El trapero de Madrid } & \text { La tía de Carlos } \\ \text { Por las nubes } & \text { Mi cara mitad } \\ \text { Aire de fuera } & \text { Mariana } \\ \text { Las de Caín } & \text { Don Juan Tenorio } \\ \text { La viuda de López } & \text { El amor asusta } \\ \text { De mala raza } & \text { El chiquillo } \\ \text { El flechazo } & \text { El jorobado. } \\ \text { La caja de caudales } & \end{array}$

La primera impresión que produce en la crítica es bastante buena, no así en la concurrencia, que no es ni con mucho lo abundante que debía ser. Se lee en la prensa:

Anoche y con una regular entrada, debutó en el decano de nuestros coliseos la Compañía Cómico-Dramática que dirige el aventajado Primer 
Actor y Director del Teatro de la Comedia de Madrid, don Francisco García Ortega. La obra elegida para el debut fue «Felipe Derblay», cuya interpretación fue esmerada, distinguiéndose las Sras. Alverá y Nestosa, la Sta. Rodríguez y los Sres. García Ortega, Soto y Valle. Las Sras. Blanco y Bagá, la Sta. Peña y los Sres. Aguado, Rande, Porredón, Norro, López, Barrera, Agudín y Fernández coadyuvaron al buen éxito de la traducción francesa. El vestuario y la mise en escena con mucha propiedad y buen gusto. Todos los artistas fueron llamados a escena al final de cada acto. La temporada promete ser de buenos resultados (El Noticiero, $\mathrm{n} .^{\circ} 1425$, 25-IV-02, p. 3).

En su segunda estancia en Alicante, a caballo entre 1909 y 1910, dijo la prensa:

\begin{abstract}
Anoche salió complacidísimo el público de la interpretación dada a las obras que figuraban en el cartel por los artistas de la compañía que dirige el Sr. García Ortega. En primer lugar se puso en escena "Doña Clarines», en la que fue muy celebrada la Sta. Méndez, que se nos reveló como una ingenua adorable y la Sra. Alverá, que dio a su papel de Tatá todo el carácter con que soñaron los hermanos Quintero. La Sra. Nastosa nos llegó a convencer definitivamente, siendo de justicia consignar que tuvo aciertos plausibles en determinadas escenas.

El héroe de la noche fue Francisco García Ortega, que en la interpretación del papel de D. Basilio estuvo colosal y muy superior a Balaguer, único actor a quien hemos visto representar «Doña Clarines» y con el que podemos compararle. García Ortega hizo el tipo de borrachín degenerado de modo acertadísimo. En el hablar, en el gesto, logró convencer a la concurrencia de sus grandes condiciones de actor, siendo para él todos los aplausos y todos los elogios.
\end{abstract}

Luego de "Doña Clarines», nos fue servida a guisa de postre sabroso una linda joya benaventiana: "El marido de su viuda», juguete cómico improchable (sic) como hijo de la sin par pluma que lo escribió. No hay en él trascendental problema alguno planteado. Benavente no ha querido con su nueva obra más que entretener al publiquito y de si logra sus propósitos pueden dar fe los concurrentes a la función de anoche que riereon grandemente al ver las desvergüenzas del chantajista, del vividor Caralonga y sus recursos vergonzosos para salir airoso en sus aficiones a la esgrima del sable. La interpretación dada a la obra fue irreprochable por parte de todos los artistas y muy especialmente por la de la Sra. Nestosa y el Sr. García Ortega (Diario de Alicante, n. ${ }^{\circ} 856,17-\mathrm{XII}-09$, p. 2).

En la reseña aparecida al día siguiente vemos, no obstante, que ni el crítico ni el público salieron contentos de la función, a pesar de la indudable categoría de la compañía:

Benavente, el único, triunfó una vez más. El gran ingenio del autor insigne se adapta a las formas de la dramaturgia y en el juguete cómico, en el sainete, en la comedia y en el drama sale triunfador siempre en su talento. Con «Los ojos de los muertos» hace un alarde más de su genio. 
Pero no puedo hoy como otras veces echar las campanas al vuelo en señal de alborozo: su triunfo será efímero y no quedará una hoja de laurel, dentro de poco, que unir a la gloriosa corona que ciñe las sienes del autor de "La gobernadora». Es la obra estrenada anoche un drama sombrio, tétrico, trágico, con dejos ibsenianos y factura echegarayesca. La estructura de los monigotes que juegan en el desenvolvimiento de la acción es bien distinta de la de cuantos creara su imaginación. Benavente se aparta de la senda recorrida y no sufre extravios; pero justo es consignar que por el nuevo camino emprendido no anda con la soltura y con el desenfado, con la seguridad con que anduvo siempre.

El público no salió satisfecho de la obra. En honor a la verdad he de decir que "Los ojos de los muertos» no entusiasmó grandemente a la concurrencia, que prefiere ver a Benavente en su terreno que verlo pisando tierra ajena (Diario de Alicante, $\mathrm{n} .{ }^{\circ} 857,18-\mathrm{XII}-09, \mathrm{p} .3$ ).

Esta compañía permanece en Alicante hasta el 10 de enero y quizá lo más reseñable sea el hecho de haber representado una obra fuera de su momento habitual. Me refiero a $D$. Juan Tenorio, que siempre se interpretaba en los días próximos al 1 y 2 de noviembre. Sobre esto afirmaba la crítica:

A estas alturas poner en escena el «Tenorio» era una temeridad plausible de García Ortega. Temeridad por el éxito de taquilla, que fue funesto, plausible porque el distinguido actor nos quiso dar una muestra más de su talento interpretando el legendario personaje que creara Zorrilla.

García Ortega hizo un "Burlador de Sevilla» admirabilísimo, como jamás recordamos haber visto otro. Vestido con propiedad acabada, no perdonó detalle ni gesto adecuado para llevar al público la impresión justa de lo que el D. Juan debe ser, no lo que otros actores quieren que sea. Huyó del socorrido latiguillo y dijo las tiradas de versos zorrillescos de modo singular.

García Ortega es un autor siempre aplaudido en el arte de hacer comedias: en los dramas y tragedias no está a la altura de su fama porque estos géneros no se avienen a sus condiciones de artista pero anoche en el "Tenorio» estuvo sencillamente admirable. Los aplausos que el público le dedicó fueron grandes y merecidísimos (Ecos, Diario de Alicante, $\mathrm{n}^{\circ} 868$, 4-I-10, p. 1).

\section{COMPAÑía LÍRICA DE PABLO GORGÉ}

Esta compañía contaba con la participación de los siguientes artistas:

$\begin{array}{llll}\text { Manuel Penella, } & \text { Maestro Concertador } & \text { Rafael Sancho } & \\ \text { Ramona Gorgé } & \text { Emma Silva } & \text { Rafael Bazares } & \text { Lucio Delgado. }\end{array}$


Actuaron en el Teatro Principal desde el día 1 de diciembre de 1906 hasta el 7 de enero del año siguiente. Las obras representadas eran casi todas de tres actos, por lo que no cabían las funciones por secciones. Por ello, se programó una sola función diaria, a las 21 horas, a la que se añadía otra a las 16 horas en los días festivos. Hubo dos días en que se modificó el horario: el día 24 (Nochebuena) y el 31 (Nochevieja), con una función a las 18,30 horas. Las obras representadas fueron:

$\begin{array}{llll}\text { La tempestad } & \text { La canción del náufrago } & \text { Cavalleria rusticana } & \text { El rey que rabió } \\ \text { Campanone } & \text { Las campanas de Carrión } & \text { La Bohème } & \text { La bruja } \\ \text { El juramento } & \text { Los pícaros celos } & \text { Las dos princesas } & \text { Marina } \\ \text { El trovador } & \text { El milagro de la Virgen } & \text { El diablo en el poder } & \text { Rigoletto } \\ \text { El anillo de hierro } & \text { Jugar con fuego } & \text { El postillón de la Rioja } & \text { La Marsellesa } \\ \text { Los sobrinos del capitán Grant } & \text { La marcha de Cádiz } & \text { Bohemios } & \text { Las dos princesas } \\ \text { La alegría de la huerta } & \text { El reloj de lucerna } & \text { Marieta } & \text { La guerra santa. }\end{array}$

Un baile de máscaras

Tuvo esta compañía la mala suerte de encontrarse con los graves disturbios sociales en Alicante, que finalizaron con un trágico balance de muertos y heridos. Por ello, desde el día 2 al 5 de enero, el teatro registró muy poca asistencia, cosa lógica en esas circunstancias.

De nuevo en 1907 actuó la compañía en el Principal, desde el día 7 al 12 de febrero, ocupando su escenario Pablo Gorgé junto con:

$\begin{array}{llll}\text { Ramona Gorgé } & \text { Consuelo Soler } & \text { Juana Sánchez } & \text { Emilia López } \\ \text { Asunción Benet } & \text { Pedro Tapias } & \text { Francisco Mariner } & \text { Leopoldo Delgado. } \\ \text { Antonio Montañana } & \text { Ramón Casas } & & \end{array}$

Pusieron en escena:

La Marsellesa

La mascota

Marina
El trovador

El dúo de la Africana

El rey que rabió
La alegría de la huerta

Las campanas de Carrión

Miss Helyett.

Y en 1908, actúa de nuevo en el Principal, desde el 5 al 13 de diciembre, representando: 


$\begin{array}{llll}\text { Jugar con fuego } & \text { La tempestad } & \text { La golfemia } & \text { Sangre moza } \\ \text { La Czarina } & \text { Marina } & \text { Rejas y votos } & \text { La bruja. } \\ \text { El milagro de la Virgen } & & \text { Los diamantes de la corona } & \end{array}$

\section{COMPAÑÍA DRAMÁTICA DE MARÍA GUERRERO Y FERNANDO DÍAZ DE MENDOZA}

En 1901 se produjo un gran acontecimiento teatral en Alicante: la presentación de quienes durante bastantes años habrían de ser los reyes de la escena, los más apreciados artistas en todos los escenarios y los dueños de la compañía por la que cualquier actor deseaba desfilar.

La prensa, desde varios día antes del debut, estuvo insistentemente haciendo la presentación de la compañía y de sus actores y actrices, en particular de María y Fernando. Cantaban las excelencias de ambos y, con ello, animaban al público a una masiva asistencia al teatro, como efectivamente sucedió en todos los días en que actuaron. Con todo ello se consiguió un extraordinario éxito, tanto económico como de representación durante los días 31 de enero hasta el 21 de febrero. Entre los componentes de la compañía destacaban:

$\begin{array}{llll}\text { Carlos Allen Perkins } & \text { Ricardo Calvo } & \text { Leovigildo Tatay } & \text { Fernando Villalonga } \\ \text { Dolores Arnau } & \text { Encarnación Bofill } & \text { Julia Martínez } & \text { Matilde Bueno. }\end{array}$

Los precios eran más elevados que en temporadas anteriores y la entrada costaba una peseta. Con la magnífica propaganda realizada, se logró que el público, además de acudir en masa, llegara mentalizado de que había de ver algo grandioso. Representaron estas obras:

El vergonzoso en palacio
Los dos habladores
Tierra baja
El loco Dios
La Pepa
Las cuatro esquinas
Mancha que limpia
La mujer del sereno

A cadena perpetua
María Estuardo
Locura de amor
El desdén con el desdén
El dragoncillo
Lo positivo
Mensajero de paz
El señor gobernador

El estigma

La sota de bastos

De la China

Mariana

La niña boba

Las citas

La Praviana

Hija y madre. 
La estancia de María Guerrero en Alicante estuvo plagada de importantes acontecimientos de variada índole. Uno de ellos, y por cierto de signo luctuoso, fue el fallecimiento aquí de su padre, por lo que, a pesar de estar agotado el taquillaje, se suspendieron las representaciones del día 3 de febrero, al tiempo que la actriz recibía numerosas y sentidas muestras de condolencia.

Los otros acontecimientos tuvieron otro cariz. Verdaderamente enardecía a los espectadores, tanto a los de elevada cultura y capacidad de valorar debidamente el teatro, como al pueblo llano que acudía a pesar de las dificultades económicas y se emocionaba igualmente con artistas de mayor talla que los que estaba acostumbrado a ver. Se hablaba de ella y también de Díaz de Mendoza, se comentaban las funciones, se discutían situaciones y se llenaron muchas páginas de periódicos con sus nombres. Éste es un ejemplo:

\author{
A MARÍA GUERRERO \\ Te vi reír!... La luz de la alborada \\ enjugaba el rocío de las flores \\ y requería el ruiseñor de amores \\ a su fiel compañera en la enramada \\ Te vi llorar!... La tempestad airada \\ estalló con siniestros resplandores \\ y escuché entre lamentos y dolores \\ el estertor de un alma desgarrada. \\ No te ofenda María, ni te asombre \\ que ante el genio que Dios te ha concedido \\ este humilde poeta sin renombre \\ ponga a tus pies un corazón honrado \\ y que ha reído cuando tú has reído \\ y que ha llorado cuando tú has llorado. \\ Genaro Calatayud Bonmatí \\ (El Noticiero, n. ${ }^{\circ}$ 1.005, 12-II-01).
}

Rodríguez Méndez (1974: 128-129) califica de horrendos otros versos dedicados a la actriz:

Dios te salve, María Guerrero llena eres de gracia, el Señor es contigo y bendita tú entre todas las actrices $y$ bendito es el fruto de tu padre Ramón

y afirma sobre ella: 
María Guerrero fue eso: laboriosidad incansable, humildad extrema, tesón, entusiasmo. Hizo de su vida teatro. Se encerró definitivamente en su teatro, del que hizo bastión de su gran personalidad. En su tiempo, María Guerrero sólo pudo llevar a cabo lo que hizo: crear un centro de irradiación teatral; domesticar a las muchedumbres por el sortilegio del teatro. [...] No, indudablemente nunca jamás, en toda la historia de nuestro teatro existió una personalidad tan arrolladora y fantástica como la de María Guerrero Torija.

Durante la estancia de la compañía en Alicante, se celebró el estreno de El loco Dios. Asistió al teatro su autor, José Echegaray, uno de los dramaturgos de más prestigio en el momento y, por la noche, se le tributó un grandioso homenaje en los salones del Casino, con asistencia de autoridades, de los componentes de la compañía y, en general, del «todo Alicante». En él intervinieron diferentes personalidades de la vida política y cultural de la ciudad, que elogiaron la grandeza de Echegaray, avalada por el ruidoso éxito de la función de la tarde. La prensa recogió como muy significativos dos poemas dedicados al escritor: uno, firmado y recitado por el poeta alicantino Carmelo Calvo:

Locura es hoy hablar y en mí sería gran dicha en estos críticos instantes ser loco cual el loco que Cervantes concibió en su inspirada fantasía.

$Y$ al serlo, genio ilustre, te diría en conceptos sublimes y brillantes perteneces a raza de gigantes que fue el asombro de la patria mía.

Mas como nada valgo, me envanezco de verte entre nosotros y enmudezco al par que te saludo reverente.

$Y$ al callar la razón no me demandes: son el genio y el sol astros tan grandes, que nos ciega su luz vistos de frente.

(El Noticiero, n. $\left.{ }^{\circ} 1008,15-\mathrm{II}-01\right)$.

Y otro, original de Martínez Torrejón, pero en el que simula que está escrito por el médico alicantino, Dr. Esquerdo (de Villajoyosa), en el que con términos propios de su especialidad (psiquiatría) define a Echegaray y al personaje de su obra, Gabriel Medina:

Tu Loco-Dios aplaudí y francamente, José no sé si explicar podré lo que al oírlo sentí
Por tener yo aquí un Medina diera toda mi clientela pues su locura divina nos atrae y nos fascina 
y lo que más admiré.

¿Qué gallardo es tu Gabriel!

¿Qué sublime su locura...!

Al estudiar su figura

no sé si hay locura en él

o hay exceso de cordura.

Dicen que un loco hace ciento

y yo aunque fe pueda dar

de que eso es sólo un invento

te confieso que un momento

al verlo llegué a dudar;

pues te digo, sí señor,

que al escucharlo hay muy pocos

no se vean en rigor

rematadamente locos

de entusiasmo... por su autor.

Mira si habré yo estudiado

casos de enajenación,

nunca en mi vida he observado

uno que me haya causado

tan profunda admiración. nos halaga y nos consuela.

¿Gloria al inmortal autor

de tan hermosa figura!

Ella a su insigne creador

cercara de ese fulgor

Que no se extingue y perdura.

Loor, pues, al que ideando

locura tan peregrina

rastro de gloria divina

ha conseguido ir dejando

por donde pasa Medina.

Y gloria también a aquél

que dejó su obra genial

como otros con su pincel

una pareja inmortal:

a Fuensanta y a Gabriel.

$Y$ ahora tú, sabio doctor, perdóname si, atrevido, tu secreto ha sorprendido y el supuesto borrador

de esta carta te ha cogido.

(El Noticiero, $\left..^{\circ} 1.008,15-\mathrm{II}-01\right)$.

Días después del homenaje, el día 22 de febrero, en sesión plenaria del Ayuntamiento de Alicante, se acuerda nombrar a Echegaray hijo adoptivo de la ciudad y, al mismo tiempo, que una de las calles principales lleve su nombre.

De nuevo, el acontecimiento de la temporada, ahora del año 1904, es la actuación de María Guerrero y su compañía, cuyos principales componentes eran en esta ocasión:

$\begin{array}{llll}\text { Margarita Colorado } & \text { Encarnación Bofill } & \text { Amparo Álvarez } & \text { María Zapata } \\ \text { Ramiro de la Mata } & \text { Francisco Palanca } & \text { Francisco Urquijo } & \text { Emilio Ariño. }\end{array}$

Hizo la compañía su presentación el día 24 de abril y se despidieron el 4 de mayo. Representaron en estos días:

$\begin{array}{llll}\text { Caridad } & \text { La desequilibrada } & \text { El abuelo } & \text { La zagala } \\ \text { Malas herencias } & \text { María Victoria } & \text { El loco Dios } & \text { La Montálvez } \\ \text { A cadena perpetua } & \text { Mensajero de paz } & \text { El viejo celoso } & \text { Por qué se ama. } \\ \text { El vergonzoso en palacio } & \text { Mancha que limpia } & \text { Los meritorios } & \end{array}$

Hay, como vemos, algunas obras nuevas respecto al año 1901 y otras que todavía las llevaban entre el repertorio, porque levantaban 
oleadas de entusiasmo, hasta el punto de que en uno de sus actuaciones, se repartieron unas octavillas por el teatro con estos versos:

\author{
A MARÍA GUERRERO \\ Para elogiar con justeza \\ tu prodigioso talento \\ es preciso que se invente \\ la lengua inmortal del Genio; \\ porque... en todos los idiomas \\ que existen bajo del cielo, \\ en todos se te ha elogiado \\ y en todos está el defecto \\ de no existir voces propias \\ dignas de ti y de tu estro. \\ A falta de ese lenguaje \\ te envío el del sentimiento.
}

Joaquín Parreño, Alicante, 3 mayo 1904.

Y, en otras octavillas, este poema dedicado al matrimonio:

\title{
A MARÍA GUERRERO Y FERNANDO DÍAZ DE MENDOZA CÓMICOS DE LA LEGUA
}

\begin{abstract}
Esa frase despectiva
que el orgullo de otros tiempos

escupió, torpe, a la cara

de pobres hermanos vuestros,

en acepción más hermosa

galantemente de ofrezco.

Sois cómicos de la legua...

pero ;a una legua del suelo!,

pues el arte del teatro

a tal altura habéis puesto

con vuestra noble constancia

y vuestro claro talento

que... imás que cosa del mundo,

parece cosa del cielo!

Y en esa acepción lo dice

mi entusiasmo y mi respeto.
\end{abstract}

Joaquín Parreño. Alicante, 3 mayo 1904.

En el año 1907 ocupa de nuevo el escenario del Teatro Principal esta compañía, que debuta el día 29 de abril y se despedirá el 5 de mayo. Cuenta ahora con estos artistas:

Julia Bárcenas

Elena Salvador

Mariano Díaz de Mendoza
Encarnación Bofill

Felipe Carsi
María Cancio

Alfredo Cirera
Luisa Gotera

Manuel Díaz. 
Representó durante estos días:

$\begin{array}{llll}\text { El genio alegre } & \text { La musa loca } & \text { Amor de artistas } & \text { El ladrón } \\ \text { Más fuerte que el amor } & \text { Mancha que limpia } & \text { Los chorros del oro } & \text { La pasadera. }\end{array}$

Para dar una idea de la expectación que siempre despertaba esta gran actriz, hay que reseñar que en el Teatro Recreo Alicantino, el día treinta, se suspendió la función tras la primera de las secciones «...para que el público pueda asistir al Teatro Principal para admirar a María Guerrero», según rezaba una escueta nota en taquillas.

Muchas muestras de la crítica favorable a María Guerrero y los suyos hubo en estos días, pero puede destacarse:

La concurrencia que se congregó anoche en el Teatro Principal fue numerosísima, compuesta casi en su totalidad por lo más distinguido de la sociedad alicantina. La obra escogida para el debut de la compañía Guerrero-Mendoza fue la preciosa comedia del inmortal Tirso de Molina, «El vergonzoso en palacio», una de las más preciosas joyas de la dramática clásica castellana. Esta obra en su primer acto despertó gran interés en el público; en el segundo produjo el más franco y ostensible sentimiento de agrado y en el tercero un entusiasmo delirante, indescriptible.

La incomparable María Guerrero, fiel intérprete de aquella enamorada mujer que concibió la mente de Tirso con el nombre de Magdalena, consiguió demostrarnos desde que apareció en escena, que no en balde la trompeta de la fama le ha otorgado singular renombre. iQué hermosura en la dicción! ¡Qué manera más inimitable de apropiarse del personaje! ¡Qué trabajo mímico más acabado! ¡Qué naturalidad! ¡Qué modo de expresar los sentimientos!

Del trabajo de su esposo, don Fernando Díaz de Mendoza en el dificil papel de Mireno, sólo elogios podemos hacer. No sin razón ha logrado escalar Díaz de Mendoza el elevado puesto que ocupa entre los actores dramáticos españoles. Anoche nos probó cumplidamente que en el género que quizá ofrece más dificultades, esto es, en la comedia clásica, no hay para él escollos

(Comiquito, El Noticiero, n. ${ }^{\circ}$ 994, 1-II-01, p. 3).

La fama de María Guerrero y de su esposo y compañero de escena se debió a muchos y variados motivos: su voz, su declamación, su estilo gestual, su acierto en la contratación de los componentes de su compañía, su señorío dentro y fuera del teatro, su fácil llegada al público y la acertada elección de las obras que representaba. Sobre este último punto, opinaba el crítico Comiquito:

Uno de los motivos por los que la gran Compañía Guerrero-Mendoza se ha hecho acreedora a los mayores laudos, es su constante y afanoso deseo 
de presentar en la moderna escena aquellas filigranas de la literatura dramática española, que nos legaron las plumas de Lope de Vega, Calderón de la Barca, Tirso de Molina, Alarcón, Rojas, Moreto, etc., es decir, las magnificas obras de nuestro talento clásico. Hoy, que el afrancesamiento todo lo domina, hoy que con tanta frecuencia vemos anunciada la 80 o 90 representación del melodrama (!) tal o cual, melodrama que no pasa de ser una atrocidad escénica traducida horriblemente, hoy, repetimos, que la dramática española se encuentra en un periodo de visible decadencia, vemos surgir ante nuestra vista una notable figura, una actriz eminente, María Guerrero, que hábilmente secundada por actor tan distinguido como Fernando Díaz de Mendoza, su esposo, trabaja con ahínco, con fe indecible, con inmenso entusiasmo, hasta resurreccionar nuestro olvidado teatro clásico

(El Noticiero, n. ${ }^{\circ} 1.001,11-\mathrm{II}-01$, p. 3).

\section{COMPAÑía CóMICO-DRAMÁTICA DE MANUEL LLORENS}

Esta compañía contaba con los siguientes componentes:

Manuel Ballart Félix Guillén José Martí Vicente Perlà Antonio Tamarit

Dolores Marsal Amparo Ramírez Loreto Bru Isabel Zamora Carmen Yáñez.

Actuaron en el Teatro Principal desde el 26 de octubre de 1904 hasta el 9 de enero del año siguiente. En esta larga estancia, representaron:

$\begin{array}{llll}\text { El señor cura } & \text { La escandalosa } & \text { A casa con mi papá } & \text { Safo } \\ \text { Don Juan Tenorio } & \text { Pepita Reyes } & \text { El chiquitín de la casa } & \text { La bohemia } \\ \text { El oso muerto } & \text { El sombrero de copa } & \text { El registro de la policía } & \text { La Tosca } \\ \text { Carlos II el Hechizado } & \text { González y González } & \text { Magdalena, la mujer adúltera La Dolores } \\ \text { El conde de Montecristo } & \text { Los de A.T.K. } & \text { Rosa la esposa mártir } & \text { Los hugonotes } \\ \text { La catacumbas de Roma o El silencio de las tumbas } & \text { Emilio Zola o El poder del genio } \\ \text { Fiacre } n .^{\circ} 13 \text { o el crimen de Nelly } & \text { Tritón o un bandido del gran mundo } \\ \text { El sepulturero del cementerio de San Nicolás } & \text { María o la hija de un jornalero. }\end{array}$

También llevaban en su repertorio obras en valenciano:

$\begin{array}{lllc}\text { El dicharachero } & \text { L'agüelo Pollastre } & \text { Mentirola o el tio Lepa } & \text { Les dos roses } \\ \text { Mil duros i tartaneta } & \text { L'escalete del dimoni } & \text { Quatre casos fulminants } & \text { Retratos al viu } \\ \text { Tres forasters de Madrid } & \text { La justicia en les mans brutes } & \text { El tio de california } \\ \text { El punt de ganxo } & \text { Matasiete espantaocho } & \text { Hostaler i serruchà } & \text { Fora baix! }\end{array}$


El tonto del panerot Les chiques del entresuelo Els besons de Sedaví LaChala

Endevina, endevinalla Una sogra de castañola La molinera de Silla Tres y... repique De Buenos Aires al serrallo El trovador en un porxe L'herencia del rey Bonet.

Casi un año después vuelve al Principal, con algunas variaciones en su elenco:
Amparo Alcina
María Bernáldez
Antonia Pellicer
Loreto Bru
Federico Augusto
Francisco Comes
Rafael Pellicer
Pedro Huarte.

Con un precio en las entradas de 0,50 pesetas, actúa la compañía desde el 7 de diciembre de 1905 hasta el 7 de enero de 1906, para poner en escena:

Los hijos artificiales

Ángela o el manuscrito de una madre

El oso muerto Los hugonotes

La cabaña de Tom o la esclavitud de los negros
Magdalena la mujer adúltera

La borracha

La aldea de san Lorenzo Vida íntima
Rosa la esposa mártir González y González María Menotti o la loca de los Alpes.

También, como era su costumbre, representaron en valenciano:

La justicia en les mans brutes

L'escaleta del dimoni

El tio cavila o A divertirse a un poblet

Una sogra de castañola
Endivina, endivinalla o el tio Perico

Els besons de Sedaví Mil duros i tartaneta

Mentirola o el tio Lepa Ineseta

Pobres i rics
La Chala.

Como curiosidad, hay que consignar dos suspensiones, aunque por motivos bien distintos. La primera, la del día de Nochebuena, según consta en un programa de mano «por no haber vendido ni una entrada» y la segunda, el día 28 de diciembre, por enfermedad del actor Federico Augusto.

\section{COMPAÑÍA CóMICO-LÍRICA DE POVEDA-FONS}

En el Principal, pasado el verano de 1904, esta compañía, cuyas principales voces eran las de Ernestina Fons y José Calvo, actuaron los 
días 9, 16 y 23 de octubre, con las obras: Marina, Los granujas y La tempestad.

Durante 1905, actúa esta compañía en el Teatro de Verano, pero sólo durante tres días $(9,10$ y 24 de septiembre). Según parece, tuvieron que suspenderse varias funciones por la lluvia y, cuando llegó el 24, cuando ya había amainado el temporal, la temperatura ya no era la apropiada. En estos días representaron:
La marcha de Cádiz
La alegría de la huerta
La Czarina
El trébol
Los pícaros celos
El bateo
El cabo primero.

El día 16 de diciembre de 1905, la compañía de Poveda-Fons inaugura el Teatro Recreo Alicantino. Nos consta que, desde ese día hasta el 31 del mismo mes, actuaron nueve días y no podemos asegurar si actuaron los días 18, 20, 23, 24, 27, 28 y 29. Representaron en estos días:

\author{
Bohemios \\ La banda de trompetas \\ El perro chico \\ Los aparecidos \\ La viejecita
}

\author{
El cabo primero \\ La alegría de la huerta \\ La marcha de Cádiz \\ El puñao de rosas \\ El bateo
}

Los pícaros celos

El trébol

El rey que rabió

La Czarina.

De nuevo, el día 5 de enero de 1906, vuelve la compañía a actuar en el Recreo Alicantino y permanece de manera intermitente hasta casi la llegada del verano, para representar:

$\begin{array}{llll}\text { El húsar de la guardia } & \text { La marcha de Cádiz } & \text { El mal de amores } & \\ \text { La alegría de la huerta } & \text { El bateo } & \text { El perro chico } & \text { La viejecita } \\ \text { La Czarina } & \text { Bohemios } & \text { La banda de trompetas } & \\ \text { El barquillero } & \text { El dúo de la Africana } & \text { La mazorca roja } & \text { Doloretes } \\ \text { Los niños llorones } & \text { El cabo primero } & \text { Las campanadas } & \text { El trébol } \\ \text { Los pícaros celos } & \text { Campanero y sacristán } & \text { El puñao de rosas } & \\ \text { La casita blanca } & \text { Marina Colorín... colorao } & \text { El rey que rabió } & \\ \text { Los cocineros } & \text { La fuente de los milagros } & \text { El pobre Valbuena } & \text { El último chulo. }\end{array}$

Vuelve al escenario del Recreo Alicantino, desde el día 13 al 30 de abril, con un elenco formado por:

Arturo R. Úbeda, como director Hipólita Martínez
Francisco Fons

Carmen Sagols
Enrique Poveda

Ernestina Fons
José Nadal

Antonia Martos. 
En esta nueva temporada alicantina pusieron en escena, con el reducido precio de la entrada, que se situó en 0,15 ptas.:

$\begin{array}{llll}\text { El cabo primero } & \text { Doloretes } & \text { Bohemios } & \text { La última copla } \\ \text { La Czarina } & \text { El contrabando } & \text { El húsar de la guardia } & \text { El perro chico } \\ \text { La alegría de la huerta } & \text { El mal de amores } & \text { El pollo Tejada } & \text { El dúo de la Africana } \\ \text { Colorín... colorao } & \text { El trébol } & \text { Los pícaros celos } & \text { Los borrachos } \\ \text { La marcha de Cádiz } & \text { El pobre Valbuena } & \text { El bateo } & \text { Marina. }\end{array}$

El puñao de rosas

En 1908, actúa esta compañía en el Teatro Principal, entre los días 16 de febrero al 2 de marzo, representando:

$\begin{array}{llll}\text { Bohemios } & \text { La cañamonera } & \text { La casita blanca } & \text { La gatita blanca } \\ \text { Sangre moza } & \text { Marina } & \text { El contrabando } & \text { Doloretes } \\ \text { El húsar de la guardia } & \text { El cabo primero } & \text { El pollo Tejada } & \text { El pobre Valbuena } \\ \text { La alegría de la huerta } & \text { La viejecita } & \text { La trapera } & \text { Moros y cristianos. } \\ \text { Campanero y sacristán } & \text { La marcha de Cádiz } & \text { La rabalera } & \\ \text { La mazorca roja } & \text { El bateo } & & \end{array}$

En el mismo año de 1908, actúa en el Teatro-Cine Sport, durante los días 8 al 10 de agosto y después los días 29 y 30 del mismo mes, con las obras:

$\begin{array}{llll}\text { El dúo de la Africana } & \text { La alegría de la huerta } & \text { Bohemios } & \text { La mazorca roja } \\ \text { El pobre Valbuena } & \text { La marcha de Cádiz } & \text { Marina } & \text { El contrabando } \\ \text { La leyenda del monje } & \text { El bateo } & \text { El húsar de la guardia } & \text { Bohemios. } \\ \text { La gatita blanca } & \text { La cañamonera } & & \end{array}$

Como vemos, es ésta la compañía que en más ocasiones actuó en los escenarios alicantinos en estos diez pimeros años del siglo XX.

\section{COMPAÑÍA CÓMICO-DRAMÁTICA DE JAIME RIVELLES}

Esta compañía se presentó en el Teatro Principal el día 19 de diciembre de 1907 y permaneció en él hasta el 6 de enero del año siguiente. Figuraban en ella, además de Rivelles, primer actor y director: 


$\begin{array}{llll}\text { Amparo Guillén } & \text { María Cola } & \text { Dora Ferrer } & \text { Mercedes Nieto } \\ \text { Consuelo Nieto } & \text { María Puche } & \text { Federico Augusto } & \text { Félix Guillén. } \\ \text { Vicente Granda } & \text { Carlos León } & \text { Modesto Rivas } & \end{array}$

La entrada costaba durante estos días 0,50 pesetas y representaron en estos días:

La escalinata de un trono

La campana de la Almudaina

Un drama nuevo

María Menotti o la loca de los Alpes
La duda
Los corridos
La tosca
El vecino de enfrente
La hechicera

Esta compañía recaló de nuevo en Alicante, pero ahora en el TeatroCine Sport, donde trabajó desde el día 20 de julio al 23 de octubre de 1909. En esta larga temporada representó:

$\begin{array}{lll}\text { Los demonios en el cuerpo } & \text { Los hijos artificiales } & \text { Los Tocayos } \\ \text { La cáscara amarga } & \text { Tabaco, vino y mujer } & \text { Nicolás } \\ \text { Caerse de un nido } & \text { Inés, casta y pura } & \text { La reja } \\ \text { Varios sobrinos y un tío } & \text { Hija única } & \text { De cerca } \\ \text { El amor que pasa } & \text { La confesión } & \text { El maniquí } \\ \text { El asistente del coronel } & \text { Sin comerlo ni beberlo } & \text { Los tímidos } \\ \text { La cuerda floja } & \text { La fuerza bruta } & \text { Los asistentes } \\ \text { Zaragüeta } & \text { La cartera } & \text { Los monigotes } \\ \text { El doctor novel } & \text { Hacia la verdad } & \text { El sueño dorado } \\ \text { Por la gatera } & \text { El ratoncito Pérez } & \text { El mochuelo } \\ \text { El señor de Bobadilla } & \text { El señor de catorce } & \text { La primera postura } \\ \text { El flechazo } & \text { El hogar alegre } & \text { Los hugonotes } \\ \text { El miserable puchero } & \text { Las suegras } & \text { i la guerra! } \\ \text { El padrón municipal } & \text { El octavo no mentir } & \text { Entre doctores } \\ \text { Robo en despoblado } & \text { González y González } & \text { Los dos sordos } \\ \text { El primer rorro } & \text { El teniente cura } & \text { La cantina } \\ \text { Pepito Melaza } & \text { El genio alegre } & \text { Credulidad } \\ \text { Bodas de plata } & \text { El patio } & \text { Frankfort } \\ \text { Receta contra las suegras } & \text { Los incasables } & \text { Honra y vida } \\ \text { El noveno mandamiento } & \text { Mañana de sol } & \text { La duda } \\ \text { La campana de la Almudaina } & \text { Los corridos } & \text { Fieras mansas } \\ \text { La doncella de mi mujer } & \text { La casa de todos } & \text { Matrimonio civil } \\ \text { La olla de grillos } & \text { Las de Caín } & \text { La ducha. }\end{array}$

También representó esta compañía algunas obras en valenciano. Solían ser sainetes de no muy alto valor teatral, pero que eran el reflejo 
de la sociedad, por lo que el público los recibía de muy buena gana. Éstos fueron los representados:

Vuelve la compañía al Teatro Principal, el día 4 de diciembre de 1909 y permanece hasta el 12 del mismo mes, con los siguientes componentes:

$\begin{array}{llll}\text { Amparo Guillén } & \text { Carmen Aznar } & \text { Amparo Babi } & \text { Herminia Chiva } \\ \text { Sofía Ruiz } & \text { Dora Ferrer } & \text { Rafael Babi } & \text { Miguel Benlloch. } \\ \text { José Trescolí } & \text { Rafael Rivelles } & \text { Jaime Rivelles } & \end{array}$

Representaron en esta ocasión, con un precio de la entrada de 0,60 pesetas:

La hechicera

Los niños del hospicio

El reservista o la toma del Gurugú

Y en valenciano:
Los hijos artificiales La duda
Los amantes de Teruel Matrimonio civil.

Los dicharacheros.

De nuevo actúa la compañía en Alicante y lo hace en el Teatro-Cine Sport, desde el 7 de septiembre al 12 de octubre de 1910, con el siguiente repertorio:

$\begin{array}{lll}\text { El primer rorro } & \text { Los hijos artificiales } & \text { La cáscara amarga } \\ \text { Los dos sordos } & \text { El hogar alegre } & \text { Las de Caín } \\ \text { El teniente cura } & \text { El sueño dorado } & \text { Matrimonio civil } \\ \text { Los malhechores del bien } & \text { Frankfort } & \text { Mi cara mitad } \\ \text { El asistente del coronel } & \text { Nicolás } & \text { Robo en despoblado } \\ \text { Los intereses creados } & \text { Caerse de un nido } & \text { Hija única } \\ \text { El frac nuevo } & \text { El miserable puchero } & \text { Mil duros y mi mujer } \\ \text { Nuestra Señora } & \text { La ducha } & \text { González y González }\end{array}$


El cabo Noval, héroe y mártir

El cascabel al gato

El octavo no mentir

Casandra

La cuerda floja
Faquirismo

Ésos son otros López

Los tocayos

Los monigotes

De cerca
Bodas de plata

El noveno mandamiento

Lance inevitable

Los salteadores.

En valenciano:

El tio Cañaules

El tio de California
El dicharachero

Mentirola o el tio Lepa.

La crítica se lamentaba de la escasa asistencia de público a las funciones del Principal, a pesar de la calidad demostrada por la compañía. Esto se dijo tras su debut:

Con escasa concurrencia tuvo lugar en la noche del jueves el debut de la compañía que dirige el Sr. Rivelles con el magnífico drama trágico de don José Echegaray, La escalinata de un trono. La ejecución fue bastante esmerada por parte de todos los artistas y especialmente por parte de la Sra. Guillén, que obtuvo justos y merecidos aplausos que compartió con el señor Rivelles; los demás cumplieron como buenos resultando un conjunto muy aceptable.

No nos explicamos la continuación del retraimiento del público a nuestro principal coliseo. En cambio los cines se vieron completamente concurridos.

(El Independiente, n. ${ }^{\circ} 11,22-\mathrm{XII}-07$, p. 2).

\section{COMPAÑía CÓMICO- LÍRICA DE EMILIO DUVAL}

Fue ésta una de las compañías que en más ocasiones pisaron los escenarios alicantinos durante el periodo comprendido entre 1901 y 1910. La primera vez fue en el Teatro Principal, entre los días 28 de enero y 15 de febrero de 1904, con un elenco formado por:

Emilio Duval, como primer actor y director Mariano Liñán, maestro director y concertador Teresa Lacarra
Concepción Martí

Pilar Martí

Antonia García

El precio de la entrada fue de 0,60 pesetas. Pusieron en escena: 
Una vieja

La alegría de la huerta

La piel del diablo

Miss Helyett

Abanicos y panderetas o A Sevilla en un botijo Marina

La manta zamorana

El famoso Colirón

Los granujas
El dúo de la Africana

Venus-Salón

La golfemia

La camarona

La tempranica

El terrible Pérez

La verbena de la Paloma
El puñao de rosas

La mazorca roja

El mozo crúo

Enseñanza libre

La rifa del beso

Lola Montes

Château-Margaux.

No fue una temporada demasiado brillante, sino más bien fue considerada como de transición, ante la temporada de ópera que se avecinaba. Pero en el mismo año, el Teatro de Verano, que estaba en la plaza de Isabel II (hoy Plaza de Gabriel Miró), se trasladó al Parque de Canalejas, una calle en plena expansión en esa época y, por tanto, una zona ideal para el paseo en las plácidas noches del verano alicantino. El día 26 de junio de 1904 se inauguró el local y la temporada y para ello se contrató a la compañía de Emilio Duval, con los siguientes componentes:

Antonio Videgain, Maestro Concertador Carlota Sandford

Antonio García
Pilar Martí, Primera tiple

Carmen Sevilla

Guillermo Alba
Amparo Taberner.

Esta actriz era alicantina y durante varias temporadas mantuvo un cierto prestigio, no sólo a nivel local, sino actuando también en compañías de más prestigio y con mucho éxito. Otro de los alicientes de este teatro, que sólo funcionaba en verano, era el precio, de 0,20 pesetas por sección. Este tipo de compañías eran de las llamadas «de repertorio» y solían trabajar en funciones por secciones, equivalentes a las que en Madrid se llamaban «teatro por horas». Por eso, desde el día de la inauguración hasta la despedida, el 18 de septiembre, se representaron las siguientes obras:

$\begin{array}{lll}\text { El cabo primero } & \text { La golfemia } & \text { El trébol } \\ \text { Venus-Salón } & \text { La manta zamorana } & \text { El mozo crúo } \\ \text { Los chicos de la escuela } & \text { Abanicos y panderetas } & \text { La última copla } \\ \text { Una vieja } & \text { La mazorca roja } & \text { La fiesta de san Antón } \\ \text { Doloretes } & \text { La alegría de la huerta } & \text { La buena ventura } \\ \text { Colorín... colorao } & \text { La perla negra } & \text { El terrible Pérez } \\ \text { El perro chico } & \text { La Camarona } & \text { Los granujas } \\ \text { Agua, azucarillos y aguardiente } & \text { La inclusera } & \text { La verbena de la Paloma }\end{array}$




El barbero de Sevilla
Bohemios
Los lobos marinos
El puesto de flores
El grumete
Marina
Los pícaros celos
El pobre Valbuena
Enseñanza libre
La tempranica
La tempestad

El barbero de Sevilla

\section{Bohemios}

Los lobos marinos

El puesto de flores

El grumete

Marina

Los pícaros celos

El pobre Valbuena

Enseñanza libre

La tempestad

El barquillero
La reina mora
La patria nueva
Château Margaux
El cuñao de Rosa
La chavala
El tío de Argel
La viejecita
El dúo de la Africana
La señora capitana
Lola Montes

El famoso Colirón

La cuna

La revoltosa

La buena moza

Congreso feminista

Los pícaros celos

Gigantes y cabezudos

La tonta de capirote

Quo vadis?

La trapera.

La mayoría de estas obras eran de un solo acto, pero se da el caso de la representación de Marina (dos actos) y La tempestad (tres), para las que se representaba un acto en cada sección, de manera que el público podía verla entera (lo normal) o ver los actos que deseara. La despedida se adelantó, respecto al día previsto, porque las fuertes lluvias de otoño llegaron más pronto que de costumbre y hubo necesidad de cortar la temporada.

En 1905, la compañía actúa de nuevo en el Teatro Principal, pero en este caso, además de Duval, también es propietaria de la compañía la actriz Pilar Martí. Junto a ambos, formaban parte de la compañía:

$\begin{array}{llll}\text { Concepción Huguet } & \text { Josefina Valls } & \text { Pilar Aceves } & \text { Amalia Pueyo } \\ \text { Claudia Butier } & \text { Mercedes Márquez } & \text { Sara López } & \text { Antonio Puchol } \\ \text { Francisco Alcántara } & \text { Juan Latorre } & \text { Eugenio Morales } & \text { Valeriano Ruiz } \\ \text { José Martínez } & \text { Salvador Roldán } & \text { Antero Retes } & \text { Isidoro Morillo. }\end{array}$

El precio de la entrada era de 0,55 pesetas y tuvieron una corta estancia, desde el día 22 al 27 de abril, días en los que representaron estas obras:

El pobre Valbuena

Los chicos de la escuela

Los pícaros celos

La cuna

Bohemios

\author{
La camarona \\ El puñao de rosas \\ Las estrellas \\ El terrible Pérez \\ La perla negra
}

\author{
El barquillero \\ Enseñanza libre \\ El trébol \\ El cuñao de Rosa.
}

De nuevo actúan en 1906 en el Teatro de Verano, desde el 13 de junio al 2 de septiembre, con la incorporación a la compañía de Victoria 
Argote, Dolores Fora, Pilar Pérez, Luisa Puchol, Eduardo Álvaro, Francisco Aznar y Leandro Martín. Pusieron en escena, además de algunas de anteriores ocasiones, las siguientes novedades:

$\begin{array}{lll}\text { El lluso Cañizares } & \text { El Maestro Campanone } & \text { El dinero y el trabajo } \\ \text { Las carceleras } & \text { La cruz blanca } & \text { El perro chico } \\ \text { El aire } & \text { El túnel } & \text { La casita blanca } \\ \text { El ratón } & \text { La fosca } & \\ \text { El alma del pueblo } & \text { La vara de alcalde } & \text { Los lobos marinos } \\ \text { La borrica } & \text { Los mosqueteros grises } & \text { El maldito dinero } \\ \text { iAl agua, patos! } & \text { El arte de ser bonita } & \text { El mal de amores } \\ \text { El húsar de la guardia } & \text { Marí Luisa } & \text { El pollo Tejada } \\ \text { El corral ajeno } & \text { La gatita blanca } & \text { San Juan de Luz. } \\ \text { Moros y cristianos } & \text { La alegres modistillas o El botijo de Alicante } \\ \text { El contrabando } & \end{array}$

Hay que destacar, como anécdota, que los días 14 y 15 de junio se suspendieron las funciones por la lluvia, así como el día 2 de septiembre, en que «...llovió tanto que hubo que sacar actrices en brazos y los muebles y enseres iban nadando» y que en las funciones de los días 29 de junio y 12 y 19 de agosto, en los programas de mano se indicaba como hora de inicio de la función «después de la corrida de toros».

Y por último, vuelven a actuar en el Teatro de Verano en la temporada de 1909, desde el día 23 de junio hasta el 1 de septiembre. Ahora, la compañía la formaban:

$\begin{array}{llll}\text { Arturo de Isaura, } & \text { maestro concertador } & \text { Cándida Suárez } & \text { Dolores Ruiz } \\ \text { Blanca Suárez } & \text { Amalia de Isaura } & \text { Ángela Figuerola } & \text { Antero Retes. } \\ \text { Valentín González } & \text { Arturo Suárez } & \text { Luis Antón } & \end{array}$

El repertorio incluía piezas ya representadas en otras ocasiones, junto a otras que habían ido añadiendo año tras año. Estas obras fueron las representadas:

$\begin{array}{llll}\text { El puñao de rosas } & \text { El barbero de Sevilla } & \text { Los mosqueteros } & \\ \text { El terrible Pérez } & \text { La vara de alcalde } & \text { El dinero y el trabajo } & \\ \text { La gente seria } & \text { El hurón } & \text { Musetta } & \text { La guardia amarilla } \\ \text { La contrata } & \text { El húsar de la guardia } & \text { El señor Joaquín } & \\ \text { El pobre Valbuena } & \text { La muñeca ideal } & \text { La tempranica } & \text { Lola Montes } . \\ \text { Los granujas } & \text { La alegría del batallón } & \text { El dúo de la Africana } & \end{array}$


Francisco ReUS Boyd-SwaN

La suerte loca El pollo Tejada

Los hombres alegres Las bribonas

La viuda alegre

El grumete

El método Górritz

La fiesta de san Antón
Partida disuelta

El perro chico

El bello Narciso

Aquí hase farta un hombre
La alegre trompetería

Bohemios Alma de Dios

La mazorca roja

La manzana de oro Bocaccio

El trébol

La viejecita

La temporada finalizó antes de lo previsto, debido al fuerte temporal de lluvia que cayó sobre Alicante en los primeros días de septiembre.

Por nuestra parte, cerramos este telón... 